Aufbruch im Dorf 


\section{Aufbruch im Dorf}

Strukturwandel im ländlichen Raum

Baden-Württembergs nach 1950

Von Gunter Mahlerwein

J.B.METZLER 



\section{Inhaltsverzeichnis}

\section{Aufbruch im Dorf 9}

\section{Bilder von der Landwirtschaft $\quad 15$}

Vor dem Umbruch: Landwirtschaft um $1950 \quad 15$

Aufbruch in neue Zeiten: Die Landwirtschaft der fünfziger und sechziger Jahre 26

In der Krise: Landwirtschaft in den siebziger und achtziger Jahren 43

Zwischen Massenproduktion und Direktvermarktung:

Landwirtschaft 1990-2005 55

Zukunftsperspektiven 72

\section{Arbeit außerhalb der Landwirtschaft 75}

Die Industrie kommt in das Dorf 75

Vom Dorfhandwerker zum Dienstleister 85

\section{Dörfer ohne Bauern 93}

Vom Bauerndorf zur Wohngemeinde 93

Die Bevölkerung wächst - Stadtflucht statt Landflucht 95

Zeitweise Landflucht 104

Die Emanzipation vom Landbesitz 106

Familienbande 110

Nachbarn und andere Mitbürger 114

Zwischen Anpassung und Rebellion - Jugend auf dem Land 119

Fremde im Dorf 131

Frauen auf dem Land 140

"Zum Gespräch werden" - Soziale Kontrolle oder "Dorfluft macht frei?" 151 Vereint im Verein? 156

Die Kirche im Dorf 163 


\section{Dorfpolitik 171}

Eine Bürgenversammlung in Kirchentellinsfurt 171

Wer wird gewählt? 173

Müllabfuhr und Baulanderschließung - Themenfelder der Kommunalpolitik 179

Das Ende der Dorfpolitik? - Die Verwaltungsreform der frühen siebziger Jahre 183

"Auf dem Weg vom Dorf zur Stadt»?

Die Dörfer verändern ihr Gesicht 188

Kommunikation im Dorf 200

Das Dorf wird entdeckt 207

Dorfgeschichte als Verlustgeschichte? 213

Anmerkungen 216

Literaturverzeichnis 223

Bildquellen 232 
$\because$ F

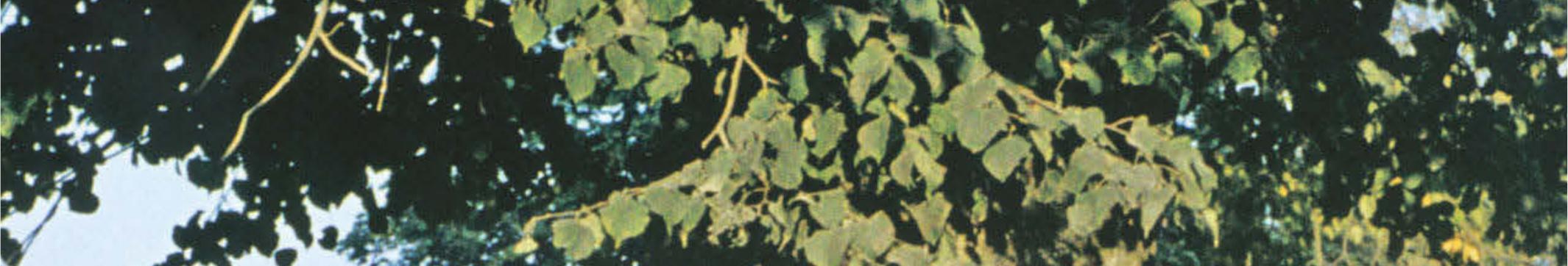

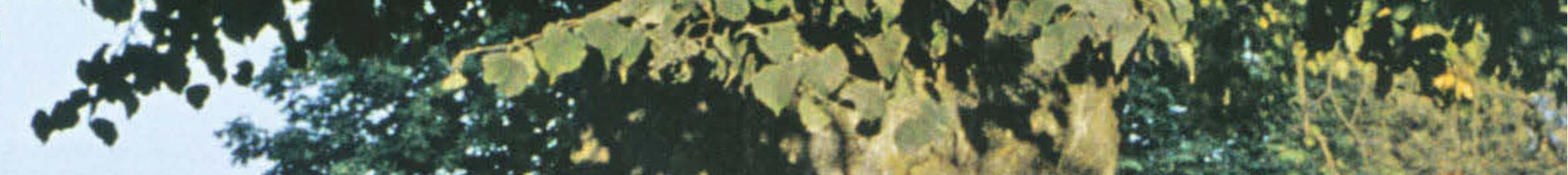

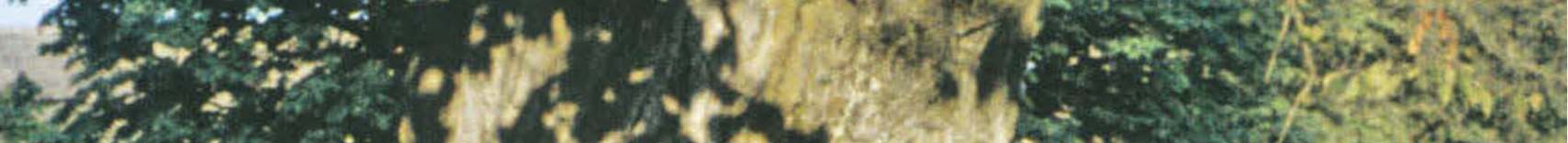

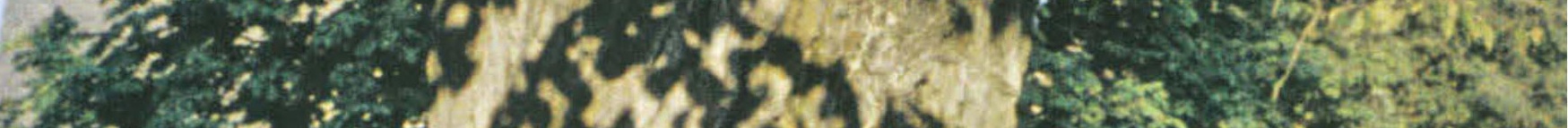

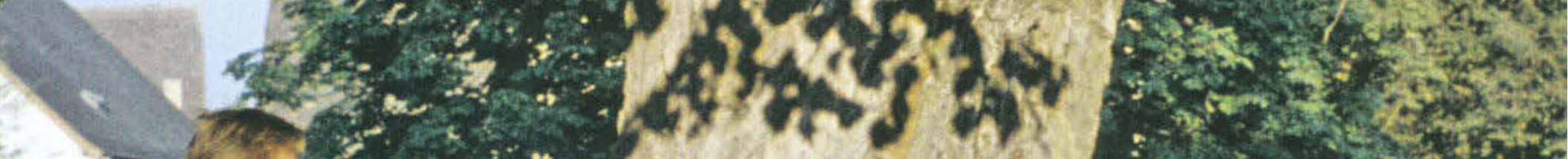

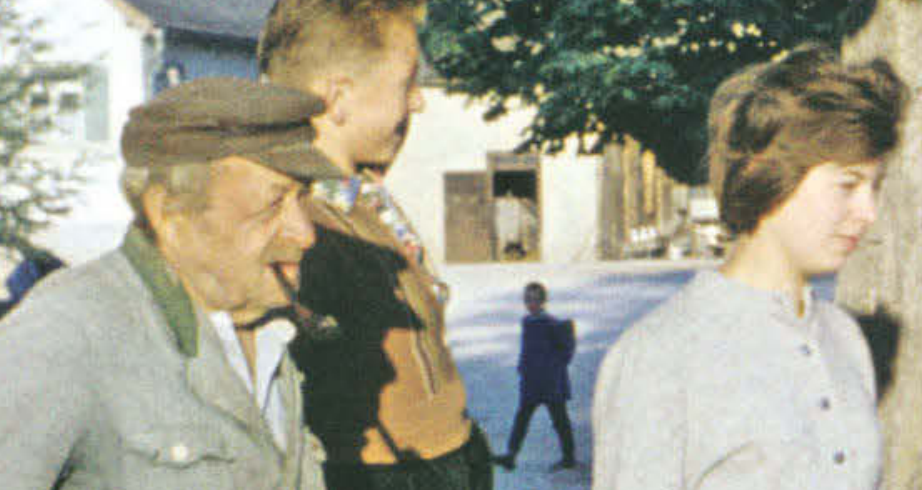

tan

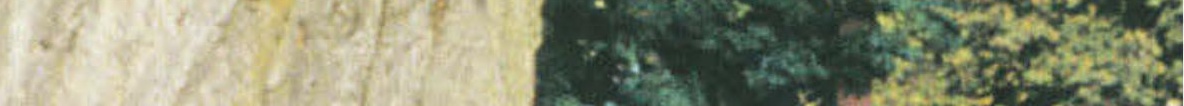
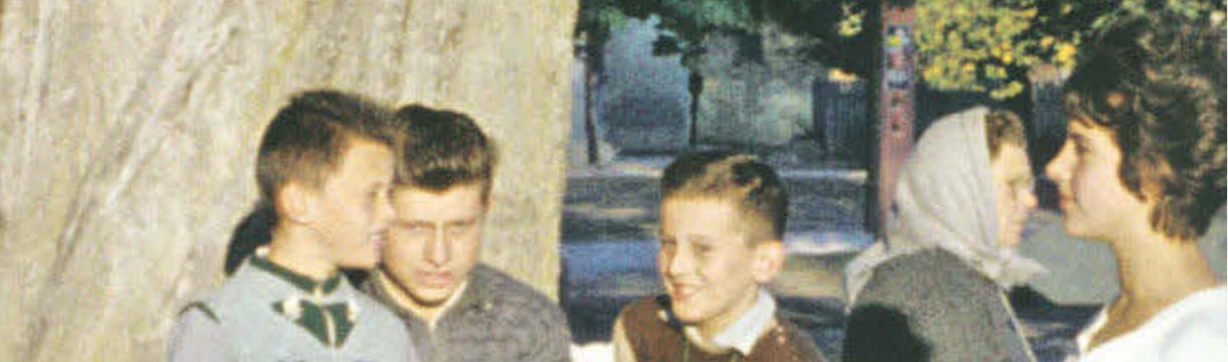